\section{SM Journal of Sleep Disorders}

\author{
Article Information \\ Received date: Jun 18, 2016 \\ Accepted date: Aug 15, 2016 \\ Published date: Sep 08, 2016

\section{*Corresponding author}

Nesreen Elsayed Morsy, lecturer of Chest Medicine, Faculty of Medicine, Mansoura University Mansoura, Egypt, E-mail: neselmorsy@yahoo.com

Distributed under Creative Commons CC-BY 4.0

Keywords Road Traffic Accidents; commercial drivers; sleepiness

Abbreviations THC: Tetra Hydro Canabinol; FOSQ: Functional Outcome of Sleep Questionnaire; ESS: Epworth Sleepiness Scale; WHO: World Health Organization; CAPMAS: Central Agency for Public Mobilization and Statistics; OSAS: Obstructive Sleep Apnoea Syndrome; NC: Neck Circumference; FTP: Friedman Tongue Position; BMI: Body Mass Index; EDS: Excessive Daytime Sleepiness

Article DOI 10.36876/smjsd.1002

\section{OPEN ACCESS}

\section{ISSN: 2576-5485}

\section{Role of Sleepiness in Road Traffic Accidents among Young Egyptian Commercial Drivers}

\author{
Ahmad Yonis Badawy ${ }^{1}$, Nesreen Elsayed Morsy ${ }^{2 *}$, Sayed Ahmad Abdelhafez ${ }^{1}$, \\ Abdel-Hady El-Gilany ${ }^{3}$ and Mohsen Mohammed EL shafey ${ }^{1}$ \\ ${ }^{1}$ Professor of Chest Medicine, Faculty of Medicine, Mansoura University, Mansoura, Egypt \\ ${ }^{2}$ lecturer of Chest Medicine, Faculty of Medicine, Mansoura University, Mansoura, Egypt \\ ${ }^{3}$ Professor of Public Health and Preventive Medicine, Faculty of Medicine, Mansoura University, Mansoura, \\ Egypt
}

\section{Abstract}

Background: Egypt is ranked the third country in the world with highest mortality rates due to road traffic accidents. The commonest cause of accidents was inattention of the driver. Driver inattention can be caused by practicing any activity other than driving or by sleepiness. Sleep at wheels can be caused by poor sleep habits, shift work, sleep disordered breathing, other sleep disorders as chronic insomnia, illicit drug abuse and medical disorders.

Methods: A cross sectional study including 324 male commercial drivers. The following data was collected history of accidents, the driving behavior including mean daily driving hours mean driving years mean daily sleep duration, shift work, seat belt, tea/coffee while driving and driving after meals. The sleepiness was assessed by history of excessive daytime sleepiness, Epworth sleepiness scale, Functional outcome of sleep questionnaire, chronic insomnia, nodded while driving, naps, risk for obstructive sleep apnea and history of comorbidities. Assessment of urine tetra hydrocanabinol (the major active ingredient in marijuana and hashish) was done. Driver's characteristic included education level, vehicle type license class road and nature of work.

Results: Prevalence of ever exposure to accidents is $25 \%$. Independent predictors of accidents were urine $\mathrm{THC}(\mathrm{OR}=5.3)$, nodding during driving $(\mathrm{OR}=4.6)$, Berlin questionnaire $(\mathrm{OR}=2.5)$, STOP Bang questionnaire $(\mathrm{OR}=1.5)$, FOSQ $(\mathrm{OR}=0.9)$, mean daily total sleep hours (continuous) $(\mathrm{OR}=0.9)$.

Conclusion: Accidents were common among studied group of drivers. It is recommended to screen drivers for urine THC, identify nodding during driving, Berlin questionnaire, STOP Bang questionnaire, FOSQ and mean daily total sleep hours to predict the driver with high risk of the sleep related accidents.

\section{Introduction}

The Global status report on road safety 2015 by World Health Organization (WHO) showed that road traffic accidents (RTA) are killing around 1.25 million people annually, $90 \%$ of them in low and middle-income countries with the highest fatality in African and Eastern Mediterranean regions and RTA are the main cause of death among people aged 15-29 years (WHO, 2016). Egypt is ranked the third country all over the world with highest mortality rates due to RTA (41.6 deaths/100.000 population) (WHO, 2009).

According to the Central Agency for Public Mobilization and Statistics (CAPMAS, 2013) every hour there are three accidents, four injuries and one death, the commonest cause of accidents was inattention of the driver (18\%). Generally, inattention implies a failure to pay attention to a specific task. This failure may be due to distracting influences or due to an inability related to a physiologic factor such as sleepiness (Eberhart et al. 2000). Sleepiness at a wheel is one of the major reasons for highway accidents and fatal crashes (George, 2007). Many risk factors for the occurrence of sleepiness at the wheel exist, including long periods of wakefulness, time of day, alcohol and drug consumption, work hours, reduced sleep time, and excessive daytime sleepiness due to sleep disorders such as obstructive sleep apnea syndrome (OSAS) (Hartenbaum et al. 2006).

We conducted this study to estimate the prevalence of ever exposure to accidents and to explore their associated risk factors among young ( $\leq 40$ years) commercial drivers in Egypt.

\section{Subjects and Methods}

This is a cross-sectional study done on a convenient sample of 324commercial drivers $(\leq 40$ years) who attend to Mansoura traffic Unit - Dakahlia governorate - Egypt for renewal of commercial license during the duration (from November 2014 to October 2015). After the Ethical approval has been obtained from Medical Research Ethics Committee, Faculty of Medicine, Mansoura University, all commercial drivers with $\leq 40$ years were subjected to full history taking include: 
1-personal history (age, comorbidities, smoking), 2-characteristic of the driver (e.g. Vehicle type, license class include first: the most skilled driver who can drive any vehicle type, second: drivers who can drive all vehicles of the third class plus trucks with medium weights and bus with (up to 26 passengers), third: drivers who can drive

Table 1: General data in both groups.

\begin{tabular}{|c|c|c|c|}
\hline & $\begin{array}{l}\text { I- PERSONAL } \\
\text { HISTORY }\end{array}$ & $\begin{array}{c}\text { No } \\
\text { accident } \\
(243) \\
\mathrm{N}(\%)\end{array}$ & $\begin{array}{c}\text { Significance } \\
\text { test }\end{array}$ \\
\hline \multicolumn{4}{|c|}{ I- PERSONAL HISTORY } \\
\hline Age (mean $\pm S D)$ & $32.7 \pm 5.2$ & $32.1 \pm 4.9$ & $\mathrm{t}=0.9, \mathrm{P}=0.4$ \\
\hline Comorbidities & $3(3.7)$ & $3(1.2)$ & $X^{2}=2.03, P=0.2$ \\
\hline $\begin{array}{c}\text { Smoking } \\
\text { Smokers } \\
\text { Non smokers }\end{array}$ & $\begin{array}{l}26(32.1) \\
55(67.9)\end{array}$ & $\begin{array}{c}82(33.7) \\
158(65)\end{array}$ & $X^{2}=1.1, P=0.6$ \\
\hline \multicolumn{4}{|c|}{ II- QUALITY OF THE DRIVER } \\
\hline $\begin{array}{c}\text { Vehicle type } \\
\text { Heavy truck } \\
\text { Light truck } \\
\text { Car }\end{array}$ & $\begin{array}{c}45(55.6) \\
9(11.1) \\
27(33.3)\end{array}$ & $\begin{array}{c}72(29.6) \\
39(16) \\
132(54.3)\end{array}$ & $\begin{array}{l}X^{2}=17.8 \\
P \leq 0.001\end{array}$ \\
\hline $\begin{array}{c}\text { Road } \\
\text { Inside city } \\
\text { Short distance } \\
\text { Long distance }\end{array}$ & $\begin{array}{l}15(18.5) \\
40(49.4) \\
26(32.1)\end{array}$ & $\begin{array}{c}54(22.2) \\
140(57.6) \\
49(20.2)\end{array}$ & $X^{2}=4.9, P=0.09$ \\
\hline $\begin{array}{l}\text { License class } \\
\text { First } \\
\text { Second } \\
\text { Third }\end{array}$ & $\begin{array}{c}33(40.7) \\
13(16) \\
35(43.2)\end{array}$ & $\begin{array}{c}45(18.5) \\
65(26.7) \\
133(54.7)\end{array}$ & $\begin{array}{l}X^{2}=16.9 \\
P \leq 0.001\end{array}$ \\
\hline $\begin{array}{l}\text { Education level } \\
\text { Above secondary } \\
\text { Secondary } \\
\text { Below secondary }\end{array}$ & $\begin{array}{l}15(18.5) \\
40(49.4) \\
26(32.1)\end{array}$ & $\begin{array}{c}27(11.1) \\
140(57.6) \\
76(31.3)\end{array}$ & $X^{2}=3.3, P=0.2$ \\
\hline Driving years & $12.6 \pm 5.9$ & $11.7 \pm 6.3$ & $t=1.02, P=0.3$ \\
\hline Daily driving hours & $10.8 \pm 4.9$ & $9.7 \pm 5.2$ & $\mathrm{t}=1.8, \mathrm{P}=0.08$ \\
\hline \multicolumn{4}{|c|}{ III- DRIVING BEHAVIORS } \\
\hline Naps & $55(67.9)$ & $107(44)$ & $\begin{array}{l}X^{2}=13.8 \\
P \leq 0.001\end{array}$ \\
\hline Nodding while drive & $24(29.6)$ & $18(7.4)$ & $\begin{array}{l}X^{2}=26.6 \\
P \leq 0.001\end{array}$ \\
\hline Daytime Sleepiness & $16(19.8)$ & $17(7)$ & $\begin{array}{l}X^{2}=10.8 \\
P=0.002\end{array}$ \\
\hline Shift work & $53(65.4)$ & $112(46.1)$ & $X^{2}=9.1, P=0.003$ \\
\hline Tea/coffee while driving & $34(42)$ & $77(31.7)$ & $X^{2}=2.9, P=0.09$ \\
\hline $\begin{array}{c}\text { Mean Daily total sleep } \\
\text { hours }\end{array}$ & $5.0 \pm 2.2$ & $6.1 \pm 2.6$ & $\mathrm{t}=3.5, \mathrm{P}=0.001$ \\
\hline
\end{tabular}

Car (including taxi, private cars); BMI: body mass index.

Table 1 shows that: No significant difference was found in personal history (age, comorbidities and smoking habit) ( $p=0.4,0.2$ and 0.6 respectively). Higher percentage of accidents was found in those with heavy truck (55.6\%) in comparison to car $(33.3 \%)$ and light truck $(11.1 \%)$, these differences were statistically significant $(p \leq 0.001)$. also higher percentage of accidents was found in third license class $(43.2 \%)$ followed by first class $(40.7 \%)$ and the last was found in second class $(16 \%)$. While no significant difference as regard other parameters of quality of drivers: road, educational level, driving years and mean daily driving hours $(p=0.09,0.2,0.3$, and 0.08 respectively). There are significant higher percentages of accidents in drivers who had history of napping $(67.9 \%)$, shift work (65.9\%), nodding while driving (29.6\%), daytime sleepiness (19.8\%) and significan difference as regard mean daily total sleep hours ( $5 \mathrm{~h}$ vs 6.1 ) in comparison to those without accidents $(p \leq 0.001,=0.003, \leq 0.001,=0.002,=0.001$ respectively) while no significant differences as regard tea/coffee while driving. cars, taxi and minibus (not more than 17 passengers), usual work road, educational level, mean daily driving hours and driving years (for assessment of fatigue)), 3-driving behaviors by (Naps, Nodding while drive, Daytime Sleepiness, Shift work, Tea/coffee while driving, mean daily total sleep hours (for assessment of sleep deprivation), 4-clinical examination (Neck Circumference (NC) (Davies et al. 1992). Friedman Tongue Position (FTP) (Friedman et al. 2002), mallampati score (Mallampati et al. 1985), Hypertension (systolic and diastolic)), 5-Scales and Questionnaire (FOSQ (for assessment of effect of sleepiness on daytime activities) (Chasens et al. 2009), ESS (for assessment of sleepiness) (Johns, 1991), Friedman OSAHS score (Friedman, 2009), STOP Bang score (Chung et al. 2008), Berlin Questionnaire (Netzer et al. 1999)), Berlin, Friedman OSAHS score, STOP Bang scores, NC were used for assessment of risk of obstructive sleep apnea 6-laboratory examination (urine tetrahydrocannabinolTHC for cannabis drug abuse assessment, other drugs abuse assessment were excluded because of the cost limitations). Although alcohol consumption can be a problem in many countries, but its use is prohibited in Egypt and drivers will deny the consumption, so it was excluded in our work. Then we classified the studied subjects into two groups based on presence or absence of history of exposure to sleep related accidents. Data was analyzed using SPSS version 16 . Qualitative variables were presented as number and percent. Chi

Table 2: Comparison between both groups of commercial drivers by clinical and laboratory variables.

\begin{tabular}{|c|c|c|c|}
\hline & $\begin{array}{c}\text { Accident } \\
\text { (81) }\end{array}$ & $\begin{array}{c}\text { No accident } \\
(243)\end{array}$ & Significance test \\
\hline \multicolumn{4}{|l|}{$\begin{array}{l}\text { IV-CLINICAL } \\
\text { EXAMINATION }\end{array}$} \\
\hline NC & $40.1 \pm 2.5$ & $38.8 \pm 4.3$ & $\mathrm{t}=2.5, \mathrm{P}=0.02$ \\
\hline Hypertension (systolic) & $24(29.6)$ & $39(16)$ & $X^{2}=7.2, P=0.01$ \\
\hline Hypertension (diastolic) & $36(44.4)$ & $72(29.6)$ & $X^{2}=6.0, P=0.02$ \\
\hline FTP & $2.9 \pm 1.3$ & $2.9 \pm 1.4$ & $\mathrm{t}=0.3, \mathrm{P}=0.7$ \\
\hline Modified Mallampati score & $2.3 \pm 0.9$ & $2.3 \pm 0.9$ & $\mathrm{t}=0.3, \mathrm{P}=0.9$ \\
\hline \multicolumn{4}{|l|}{$\begin{array}{l}\text { V-SCALES AND } \\
\text { QUESTIONNAIRES }\end{array}$} \\
\hline FOSQ & $35.2 \pm 3.4$ & $37.3 \pm 2.6$ & $t=5.6, p \leq 0.001$ \\
\hline ESS & $4.8 \pm 3.4$ & $2.7 \pm 2.6$ & $Z=5.0, P \leq 0.001$ \\
\hline Friedman OSAHS score & $6.6 \pm 2.1$ & $6.2 \pm 1.9$ & $\mathrm{t}=1.9, \mathrm{P}=0.07$ \\
\hline STOP Bang score & $2.6 \pm 1.4$ & $1.7 \pm 0.9$ & $Z=5.6, P \leq 0.001$ \\
\hline Berlin Questionnaire & $1.5 \pm 1.01$ & $0.7 \pm 0.7$ & $Z=6.9, P \leq 0.001$ \\
\hline \multicolumn{4}{|l|}{$\begin{array}{l}\text { VI- LABORATORY } \\
\text { EXAMINATION }\end{array}$} \\
\hline Urine THC & $21(25.9)$ & $29(11.9)$ & $X^{2}=9.1, P=0.003$ \\
\hline
\end{tabular}

NC: neck circumference; FTP: friedmann tongue position; FOSQ: functional outcome of sleepiness questionnaire; ESS: Epworth sleepiness scale; OSAHS: obstructive sleep apnea hyponea syndrome; THC: tetrahydrocannabinol.

Table 2 shows that: There are significant higher values of body mass index ( 30.9 vs 29.1$)$ and neck circumference ( 40.1 vs 38.8$)$ also there are significant percentage of accidents in drivers with systolic $(29.6 \%)$ and diastolic $(44.4 \%)$ hypertension in comparison to those without accidents $(p=0.009,0.02,0.1,0.02$ respectively) while no significant differences as regard FTP and malampati score $(p=0.7,0.9$ respectively). As regard Questionnaires there are higher scores in drivers with accidents for FOSQ, ESS, STOP Bang and Berlin questionnaire in comparison to those without accidents (35.2 vs $37.3,4.8$ vs $2.7,2.6$ vs 1.7 , 1.5 vs 0.7 respectively) with ( $\leq \leq 0.001$ for all). As regard urine THC there are significantly higher positive tests $(25.9 \%)$ in those with accidents versus those without accidents $(p=0.003)$. 
Table 3: logistic regression analysis for independent predictors of accidents.

\begin{tabular}{|c|c|c|c|}
\hline & B & $\mathbf{P}$ & OR (Cl) \\
\hline Urine THC & 1.7 & $\leq 0.001$ & 5.3 (2.4- 11.9) \\
\hline $\begin{array}{c}\text { Nodding while } \\
\text { driving }\end{array}$ & 1.5 & $\leq 0.001$ & $4.6(1.9-10.6)$ \\
\hline $\begin{array}{c}\text { Berlin } \\
\text { Questionnaire } \\
\text { (continuous) }\end{array}$ & 0.9 & $\leq 0.001$ & $2.5(1.6-3.9)$ \\
\hline $\begin{array}{l}\text { STOP Bang score } \\
\text { (continuous) }\end{array}$ & 0.4 & $\leq 0.02$ & $1.5(1.1-2.1)$ \\
\hline FOSQ (continuous) & -0.1 & 0.03 & $0.9(0.8-0.9)$ \\
\hline $\begin{array}{l}\text { Mean daily total } \\
\text { sleep hours } \\
\text { (continuous) }\end{array}$ & -0.1 & 0.03 & $0.9(0.8-0.9)$ \\
\hline $\begin{array}{c}\text { Constant }=1.9 \\
\text { Model } \mathrm{X}^{2}=112.5 \\
\mathrm{P} \leq 0.001 \\
\text { Percent correctly } \\
\text { predicted }=82.7 \%\end{array}$ & & & \\
\hline
\end{tabular}

THC: tetrahydrocanabinol; FOSQ: functional outcome of sleepiness questionnaire; OR: odd ratio; Cl: cofidence interval.

Table 3 shows that: Multivariate analysis using binary logistic regression for statistically significant predictors in bivariate analysis. We found six independent predictors for accidents among young commercial drivers (with percentage for accuracy of this model $=82.7 \%)$ : urine $\mathrm{THC}(\mathrm{OR}=5.3)$, nodding during driving ( $\mathrm{OR}=4.6)$, Berline questionnaire (continuous) $(\mathrm{OR}=2.5)$, STOP Bang questionnaire (continuous) $(\mathrm{OR}=1.5), \mathrm{FOSQ}$ (continuous) $(\mathrm{OR}=0.9)$, mean daily total sleep hours (continuous) $(\mathrm{OR}=0.9)$. Where positive results of urine tetrahydrocanabinol and Occurrence of nodding during driving increase risk of accidents occurrence 5.3 and 4.6 times consecutively, each unit increase in Berlin and STOP Bang questionnaire increase risk of accidents occurrence 2.5 and 1.5 times consecutively. Each unit increase in FOSQ and mean daily tota sleep hours decrease risk of accidents occurrence by 0.9 for both.

square test of significance was used for comparison between groups. The Quantitative variables were presented as mean \pm SD and unpaired $\mathrm{t}$-test was used for comparison between groups. Significant predictors in bivariate analysis were entered into a logistic regression model using forward Wald method to detect the independent predictors of accidents. Adjusted odds ratios (AOR) and their 95\% CI were calculated. $\mathrm{P} \leq 0.05$ was considered to be statistically significant.

\section{Results}

All drivers are males with a mean age of $32.2 \pm 5$. Prevalence of ever exposure to accidents in the studied group was high (25\%) (81 out of 324). Prevalence of daytime sleepiness among drivers with history of accidents was $19.8 \%$. Prevalence of accidents in all drivers with history of sleepiness was very high (48\%). Prevalence of OSA risk (using STOP Bang questionnaire $\geq 3$ ) is $35.9 \%$ among all drivers with higher percentage (47.1\%) among drivers with accidents history group in comparison to non-accidents group (52.9\%) ( $\mathrm{P} \leq 0.001)$, (Tables 1-3).

\section{Discussion}

Up to our knowledge this study is the first one to address role of sleepiness in RTA among young commercial drivers in Egypt. This study revealed that one fourth (25\%) of the studied group reported exposure to accidents throughout their life and in this group around one fifth (19.8\%) had daytime sleepiness and approximately $30 \%$ experienced nodding while driving and when sleepiness was assessed with ESS, percentage decreased to (12.9\%). Around half $(48 \%)$ of drivers with history of sleepiness give history of exposure to Accidents.
We found many causes with statistically significances in studied group of accidents as mentioned previously in the results section and independent predictors of accidents was studied and we found that the independent predictors of accidents were: positive test for urine THC, occurrence of nodding during driving (sure sign of sleepiness), Berlin questionnaire result $\geq 1$, STOP Bang questionnaire result $\geq 2$, FOSQ result $\leq 35$, mean daily total sleep hours $\leq 5$ in logistic regression model.

Our independent predictors are approximately comparable with (McCartt et al. 2000) who studied long-distance heavy truck drivers and found 6 predictive factors for accidents: decreased number of sleep hours, sleep at the wheel, excessive daytime sleepiness (EDS), more hours of work and less hours off-duty, older age and experienced driver, and driving at night. The different predictors in this study may be due to use of different variables as they include elder age groups but we focused only on youth. Also they did not screen for risk of OSA byits predicting scales and questionnaires.

The most important independent predictor of accidents among commercial driver is the positive results of urine THC (OR=5.3) (25.9\% vs $11.9 \%)$. Our result is comparable with finding of Brazilian study, (Souza et al. 2005) where they found that the most common used drugs among drivers with accidents history were cannabinoids and ethanol, each found in 13\% of the drivers. In Australia, (Arnold et al. 1997) found that $23.5 \%$ used psychotropic drugs and the most prevalent drugs were cannabinoids (13.5\%). The prevalence of cannabis may be higher in our country for its cheap price (in comparison to other abused drugs) and ethanol less popular for religious and societal considerations. In a recent meta-analysis study of 367 studies, Marijuana self-reported abuse was (19.3\%) among drivers with history of accidents. In the biological samples, the authors found $(4.7 \%)$ for marijuana was found although marijuana use ranged from (0.2\%to 29.9\%) (Girotto et al. 2014).

In this study $29.6 \%$ of those with accidents had history of nodding episodes while driving which was statistically significant than $7.4 \%$ of those without accidents $(\mathrm{P} \leq 0.001)$. It is the sure sign of sleepiness during driving; our results are also comparable to the results of (Sagaspe et al. 2010) who found that around one-third of French drivers had at least one episode of sleepiness at the wheel over a one-year period. 35,004 drivers were studied by (Philip et al. 2010) and the results were high rate of sleepiness at the wheel (28\%) and a high number of accidents (11\%), 46\% of them being sleep-related, $8.9 \%$ of drivers had at least once per month an episode of sleepiness at the wheel where they had to stop driving. One-third of the drivers (31.1\%) had near-miss accidents (50\% being sleep-related), 2520 drivers $(7.2 \%)$ had a driving accident in the past year, and $146(5.8 \%)$ of these driving accidents were sleep-related.

In Sweden study over 154 lorry and bus drivers about 14\% of the drivers had regular sleepiness while driving, 33\% reported sleepiness while driving, and $8 \%$ reported experienced nodding of the head while driving (Van den Berg and Landstrom, 2006). In the United States, (McCartt et al. 2000) studied long-distance heavy truck drivers and found that $47.1 \%$ reported sleepiness at the wheel while driving just before the accidents. (Philip et al. 2014) found that the main predictive factor for road traffic accidents was having a sleepiness episode at the wheel just before the accident (OR 9.97, CI 95\%: 1.5763.50, $\mathrm{p}=0.05$ ). In our study OR for nodding while driving was (4.6). 
(BaHammam et al. 2014) found around one-fifth (20.8\%) of the Saudi drivers stopped driving because of sleepiness at least once in the past six months period and around one fourth $(25.2 \%)$ of the examined drivers experienced falling asleep at the wheel at least once also in the past six months. Another study over 430 lorry Brazilian drivers found $(22 \%)$ of drivers had history of falling asleep while driving (Canani et al. 2005). In Finland, (Hakkanen and Summala, 200) 1 found that $2.0 \%$ of the drivers had sleepiness before the accident $4.0 \%$ fatigue and $13.0 \%$ had been driving for more than 10 hours. Daytime sleepiness was observed in $26.6 \%$ of 241 longdistance drivers who were residents of Zonguldak province-turkey (Akkoyunlu et al. 2013). The mean of ESS $>10$ of accidents group was $4.8 \pm 3.4$ in our study in comparison of non-accidents group $2.7 \pm$ 2.6. In recent Turkish study drivers who reported accidents reported a significantly higher ESS scores compared with others (Ozer et al. 2014). In Brazilian study, (Souza et al. 2005) found a prevalence of $21.7 \%$ for an ESS $>10$, and significantly higher scores in the group of drivers that had an accidents. In recent Turkish 618 public transportation drivers were studied and the results were 297 (48.1 \%) had EDS. (Ozder et al. 2014) reported that there were a statistical significant differences between OSA risk (STOP Bang) and the risk of EDS ( $p=0.000)$ and a statistically significant difference in the risk of EDS (ESS $\geq 10)$ in those with past history of RTA in comparison to those without $(\mathrm{p}=0.000)$. They found that the independent predictor of excessive day time sleepiness was the OSA risk $(\mathrm{p}<0.001)$ (Ozder et al. 2014).

In New Zealand, (Connor et al. 2001) examined 588 car drivers traveling on roads using the Epworth Sleepiness Scale (ESS). They found that $3.1 \%$ of the drivers had 5 or less hours of sleep in the 24 hours before accidents, $7.9 \%$ had ESS scores between 10 and 15 and $1.3 \%$ had high scores (16 to 24). Johns and Hocking1997 examined 507 Australian workers using the ESS, and found an EDS prevalence of $10.9 \%$, which was not significantly associated with age (22 to 59 years), sex, obesity or use of drugs, but was significantly associated with a reduced number of sleep hours and insomnia. However in Iranian study there was no significant association between drivers with car accident and ESS score above 10 (Amra et al. 2012). Although in another Iranian study ESS was higher than 10 points in $9.1 \%$ of the drivers; $50.8 \%$ never fall asleep, although $36 \%$ rarely, $7.3 \%$ half of the times, $4.9 \%$ almost always and $1 \%$ always have driven drowsy (Sadeghniiat and Labbafinejad, 2007). However in our study ESS was not found as an independent predictor of accidents. Sleep-related accidents can be particularly damaging if excessive sleepiness occurs in workers responsible for safety checks, operating heavy machinery or transport. (Nakata et al. 2005).

FOSQ-10 is a self-administered 10 item questionnaire, used to assess the impact of the excessive daytime sleepiness on the daily activities. It is a tool of sleep-specific quality of life, with subscales related to activity level, vigilance, general productivity, social outcome and sexual relationships (Chasens et al. 2009). (Howard et al. 2004) studied 2,342 drivers and found that the sleepiest $5 \%$ of drivers by the Epworth Sleepiness Scale (ESS) and Functional Outcomes of Sleep Questionnaire (FOSQ) had an increased risk of an accident (odds ratio $[\mathrm{OR}] 1.91, \mathrm{p}=0.02$ and $\mathrm{OR} 2.23, \mathrm{p}=0.01$, respectively) and multiple accidents (OR 2.67, $\mathrm{p}=0.01$ and $\mathrm{OR} 2.39, \mathrm{p}=0.01$ ). In our study FOSQ has OR (0.9) for accidents.

In our study, Berline questionnaire $(\mathrm{OR}=2.5)$ STOP Bang questionnaire $(\mathrm{OR}=1.5)$ were independent predictors. Berlin (Netzer et al. 1999) and STOP Bang questionnaires (Chung et al. 2008) are used for detection of risk of obstructive sleep apnea (OSA) (one of the commonest sleep disorders). According to International Classification of Sleep Disorders Second Edition (ICSD-3) OSA is characterized by repetitive episodes of complete (apnea) or partial (hypopnea) upper airway [UA] obstruction occurring during sleep last minimally of 10 seconds associated with repeated episodes of nocturnal hypoxemia and sleep fragmentation (AASM, 2014). These recurrent episodes increase feelings of fatigue and sleepiness, which lead to increase the inattention and sleepiness while driving (George, 2007). Patients with OSA show deficits across a wide range of cognitive functions including attention, memory, psychomotor speed and visuospatial abilities, constructional abilities, executive functions and (Engleman and Joffe, 1999).

OSA is common in commercial drivers especially if itis untreated. OSA associated with a 2 to 7 fold increase in the risk of road traffic accidents (Hartenbaum et al. 2006). OSA risk among drivers with history of accidents was $47.1 \%$ in our study. A study by (Pack et al. 2002 ) found that $28 \%$ of commercial drivers diagnosed as OSA. In Malaysian study of 130 commercial truck drivers screened with Berlin questionnaire for detection of risk group of OSA and the authors found that $14.6 \%$ (19) of drivers were classified as having high risk of OSA while $85.4 \%$ (111) having low risk of OSA (Wahida et al. 2013). The higher percentage of OSA risk in our study may be due to using only a screening tool for OSA not the gold standard diagnosis by polysomnography. In a meta-analysis by (Tregear et al. 2009) they found that untreated sleep apnea is a significant cause ofroad traffic accidents. In Iranian study, the professional drivers with road traffic accidents had a higher risk in Berlin questionnaire $(\mathrm{P}<0.02)$, a larger mean neck circumference $(\mathrm{P}<0.04)$, and witnessed apneas $(\mathrm{P}<0.04)$ (Amra et al. 2012). Although in recent Turkish 618 public transportation drivers were studied and the results were OSA risk was high in $442(71.5 \%)$ drivers but there was no significant relationship between RTA and OSA risk ( $\mathrm{p}=0.06$ ) (Ozder et al. 2014).

In our study the mean daily sleep hours was significantly less in those with accidents vs those without accidents ( 5 vs $6, \mathrm{P}=0.001$, $\mathrm{OR}=0.9)$. While the total mean driving hours showed no significant difference ( 10.8 vs $9.7, \mathrm{P}=0.08$ ). these results may be due to the duration of driving was intermittent not continuous, also the total hours of driving is less than (Arnold et al. 1997) in Australia, they found that about $38.0 \%$ of the truck drivers drove for more than 14 hours per day $12.0 \%$ of the truck drivers had slept fewer than 4 hours in one or more working days in the week preceded the accidents. In the United States, (McCartt et al. 2000) studied long-distance truck drivers and found that a decreased number of sleep hours was a predictive factor of sleepiness at the wheel together with EDS, more hours of work and fewer hours of rest, older age and more experience as driver and driving at night. Studying 31,522 American drivers (Maiaa et al. 2013) found that drowsy driving was experienced more often when sleep duration was $\leq 5$ h, 6 h, or $\geq 10$ h. In Finland, (Hakkanen and Summala, 2001) found that $21.0 \%$ of the studied short-haul truck drivers fallen asleep at the wheel in $20 \%$ of their drives; reduced number of sleep hours was also a predictive factor. In a Japanese study People who sleep less than 6 hours have an increased risk of road traffic accidents (Komada et al. 2013). Manual workers with sleep features of difficulty initiating sleep, sleeping poorly at night, insufficient sleep and insomnia had a significantly higher prevalence for injury (Nakata et al. 2005). 
There are number of limitations of this study include: it is a single center study focusing on young age, absence of psychiatric evaluation, absence of objective assessment of sleepiness like multiple sleep latency tests, absence of testing for tramadol hydrochloride and other drugs abuse.

\section{Conclusion}

This study conclude that accidents were common among studied group of drivers. It is recommended to test commercial drivers for: urine THC, identify nodding during driving, Berlin questionnaire, STOP Bang questionnaire, FOSQ, mean daily total sleep hours as these will contribute to decrease the risk of accidents. These results point to the need to develop an educational programs and campaigns for commercial drivers and to improve the control by authorities with improvement of the traffic law enforcement measures aiming to reduce the high level of RTA.

\section{Acknowledgment}

The Authors would like to thank Egyptian academy for scientific research and technology and the colleagues and staff at faculty of Medicine, Mansoura University, Mansoura, Egypt.

\section{References}

1. AASM, 2014. American Academy of Sleep Medicine. International classification of sleep disorders, 3rd ed. Darien, IL: American Academy of Sleep Medicine P. 53.

2. Akkoyunlu ME, Altın R, Kart L, Atalay F, Ornek T, Bayram M, et all. Investigation of obstructive sleep apnoea syndrome prevalence among long-distance drivers from Zonguldak, Turkey. Multidisciplinary Respiratory Medicine. 2013; 8: 10.

3. Amra B, Dorali R, Mortazavi S, Golshan M, Farajzadegan Z, Fietze L, et all. Sleep apnea symptoms and accident risk factors in Persian commercial vehicle drivers. Sleep Breath. 2012; 16: 187-191.

4. Arnold PK, Hartley LR, Corry A, Hochstadt, D, Penna F, Feyer AM. Hours of work and perceptions of fatigue among truck drivers. Accid Anal Prev.1997; 29: 471-477.

5. BaHammam AS, Alkhunizan MA, Lesloum RH, Alshanqiti AM, Aldakhil AM Pandi-Perumal SR, et all. Prevalence of sleep-related accidents among drivers in Saudi Arabia. Annals of Thoracic Medicine. 2014; 9: 236-241.

6. Canani SF, Johna AB, Raymundib MG, Schonwalda S, Menna Barreto SS Prevalence of sleepiness in a group of Brazilian lorry drivers. Public Health. 2005; 119: 925-929.

7. CAPMAS, 2013. Traffic accidents in Egypt in 2013. Cairo, Egypt.

8. Chasens ER, Ratcliffe SJ, Weaver TE. Development of the FOSQ-10: A Short Version of the Functional Outcomes of Sleep Questionnaire. Sleep. 2009; 32: 915-919

9. Chung F, Yegneswaran B, Liao P, Chung SA, Vairavanathan S, Islam S, et all. STOP Questionnaire: A Tool to Screen Patients for Obstructive Sleep Apnea. Anesthesiology. 2008; 108: 812-821.

10. Connor J, Norton R, Ameratunga S, Robinson E, Wigmore B. Jackson B. Prevalence of driver sleepiness in a random population-based sample of car driving. 2001; 24: 688-698.

11. Davies RJ, Ali NJ, Stradling JR. Neck circumference and other clinical features in the diagnosis of the obstructive sleep apnoea syndrome. Thorax. 1992; 47: 101-105.

12. Eberhart R, Hu X, Foresman BH. Dangers of sleepiness and inattention while driving. J Am Osteopath Assoc. 2000: 100: 9-14.

13. Engleman H, Joffe D. Neuropsychological function in obstructive sleep apnoea. Sleep Medicine. 1999; 3: 59-78.
14. Friedman, M., 2009. Friedman tongue position and the staging of obstructive sleep apnea/hypopnea syndrome. In Sleep apnea and snoring: Surgical and non-surgical therapy book, Saunders Elsevier Inc. ISBN 978-1-4160-3112-3.

15. Friedman M, Ibrahim H, Bass L. Clinical staging for sleep-disordered breathing. Otolaryngol Head Neck Surg. 2002; 127: 13-21.

16. George C. Sleep apnea, alertness, and motor vehicle crashes, American Journal of Respiratory and Critical Care Medicine. 2007; 176: 954-956.

17. Girotto E, Mesas AE, de Andrade SM, Birolim MM. Psychoactive substance use by truck drivers: a systematic review. Occup Environ Med. 2014; 71: 71-76.

18. Hakkanen J, Summala $\mathrm{H}$. Fatal traffic accidents among trailer truck drivers and accident causes as viewed by other truck drivers. Accid Anal Prev. 2001; 33: 187-196.

19. Hartenbaum N, Collop N, Rosen I, Phillips B. Truckers with OSA, should they be driving?. J Occup Environ Med. 2006; 48: 871-872.

20. Howard ME, Desai AV, Grunstein RR, Hukins C, Armstrong JG, Joffe D, et all. 2004. Sleepiness, sleep-disordered breathing, and accident risk factors in commercial vehicle drivers. Am J Respir Crit Care Med. 2004; 170: 1014 1021.

21. Johns MW. A new method for measuring daytime sleepiness: The Epworth sleepiness scale. Sleep. 1991; 14: 540-545.

22. Johns M, Hocking B. Daytime sleepiness and sleep habits of Australian workers. Sleep. 1997; 20: 844-849

23. Komada Y, Asaoka S, Abe T, Inoue Y. Short sleep duration, sleep disorders, and traffic accidents. IATSS Research. 2013: 37: 1-7.

24. Maiaa Q, Grandnera M, Findleya J., Gurubhagavatulaa I. Short and long sleep duration and risk of drowsy driving and the role of subjective sleep insufficiency. Accident Analysis and Prevention. 2013; 59: 618-622.

25. Mallampati SR, Gatt SP, Gugino LD, Desai SP, Waraksa B, Freiberger D, et al. A clinical sign to predict difficult tracheal intubation: a prospective study. Can Anaesth SocJ. 1985; 32: 429-434.

26. McCartt AT, Rohrbaugh JW, Hammer MC, Fuller SZ. Factors associatedwith falling asleep at the wheel among long-distance truck drivers. Accid Anal Prev. 2000; 32: 493-504.

27. Nakata A, Ikeda T, Takahashi M, Haratani T, Fujioka Y, Fukui S, et all. Sleeprelated risk of occupational injuries in Japanese small and medium-scale enterprises. Ind Health. Jan. 2005; 43: 89-97.

28. Netzer N, Stoohs R, Netzer C, Clark K, Strohl K. Using the Berlin Questionnaire to identify patients at risk for the sleep apnea syndrome. Ann Intern Med. 1999; 131: 485-491.

29. Ozder A, Gunay E, Eker H, Ulasli S. Excessive daytime sleepiness among turkish public transportation drivers: a risk for road traffic accidents? Acta Medica Mediterranea. 2014; 30: 1121

30. Ozer C, Etcibası S, Ozturk L. Daytime sleepiness and sleep habits as risk factors of traffic accidents in a group of Turkish public transport drivers. Int J Clin Exp Med.2014; $7:$ 268-273

31. Pack, A.I., Dinges, D.F. and Maislin, G. 2002. A study of prevalence of sleep apnea among commercial truck drivers. FMCSA, Washington DC.

32. Philip P, Chaufton C, Orriols L, Lagarde E, Amoros E, Laumon B, et al. Complaints of Poor Sleep and Risk of Traffic Accidents: A Population-Based Case-Control Study. PLoS ONE. 2014; 9: 114102.

33. Philip P, Sagaspe P, Lagard E, Leger D, Ohayon MM, Bioulac B, et all. Sleep disorders and accidental risk in a large group of regular registered highway drivers. Sleep Medicine. 2010; 11: 973-979.

34. Sadeghniiat K, Labbafinejad Y. Sleepiness among Iranian lorry drivers. Acta Medica Iranica. 2007; 45: 149-152.

35. Sagaspe P, Taillard J, Bayon V, Lagarde E, Moore N, Boussuge J, et al. Sleepiness, near-misses and driving accidents among a representative population of French drivers. J Sleep Res. 2010; 19: 578-584. 
36. Souza JC, Paiva T, Reimao R. Sleep habits, sleepiness and accidents among truck drivers. Arq Neuropsiquiatr. 2005; 63: 925-930.

37. Tregear S, Reston J, Schoelles K, Phillips B. Obstructive Sleep Apnea and Risk of Motor Vehicle Crash: Systematic Review and Meta-Analysis. Clin Sleep Med. 2009; 5: 573-581

38. Van den Berg J, Landstrom U. Symptoms of sleepiness while driving and their relationship to prior sleep, work and individual characteristics. Transportation Research; Part F. 2006; 9: 207-226.
39. Wahida A, Ilhamah O, Suffian A, Aimi M, Norlen M, Wong S. Obstructive sleep apnea among commercial vehicle drivers in Malaysia: Issues and initiatives. Health. 2013; 5: 80-86.

40. WHO (World Health Organization). Global status report on road safety: time for action. 2009.

41. WHO (World Health Organization), 2016

42. Global status report on road safety:2015 